\section{Territórios, arquétipos e tribos}

\section{RESUMO}

O artigo tenta compreender a relação entre espaço e sociedade. Para tanto, apóia-se em Maffesoli e nos seus pensamentos sobre o espírito pós-moderno. Dá exemplos de apropriação de territórios diferentes, desenvolvendo a imagem que faz referência à angustia dos habitantes e, em consequiência, ao local na sua dimensão de 'localismo afetual', postos em cena através do arquétipo "refúgio".

\section{ABSTRACT}

This text deals with the relationship between space and society as informed by Maffesoli's views on the postmodern spirit and the archetype "refuge".

\section{PALAVRAS-CHAVE (KEY WORDS)}

- Pós-modernidade (Postmodernity)

- Espaço (Space)

- Arquétipos (Archetypes)

\section{Tânia Pitta}

Paris V/UFPE
O OBjETIVO DESTE TRABALHO é de tentar compreender a relação que existe entre espaço e sociedade em nossos quotidianos urbanos. É difícil expor toda a sensibilidade de um quotidiano urbano nestas poucas linhas, pelo fato de que os territórios são marcados por uma grande diversidade de imagens. Partiremos do princípio de que o sentimento de pertencer ao espaço é uma conseqüência direta do espírito pós-moderno. Segundo Michel Maffesoli, a sinergia entre as formas arcaicas e o desenvolvimento tecnológico transforma o convívio urbano e o espaço do cimento social em elementos diretamente influenciados pelo tempo e pelo espaço. Como poderíamos então compreender ou criar formas urbanas inspiradas nos canais de relações contemporâneos?

Irei desenvolver somente a imagem que faz referência à angustia dos habitantes e em conseqüência ao local na sua dimensão de 'localismo afetual', postos em cena através do arquétipo - refúgio. Daremos então três exemplos de apropriação de territórios diferentes: Noto, na Sicília, Morro da Conceição, em Recife, e Belleville, Paris.

Procuraremos abordar os processos que agem de maneira invisível e difusa em nossos territórios. Nota-se que o habitante das metrópoles contemporâneas procura encontrar prazer no caos em que vive, seria o que Gilbert Durand chama de bacia semântica sisifiana. Por isto, seria importante analisar os lugares de encontro afetivo que aumentam cada vez mais e não somente os 'problemas' funcionais. Procuraremos então dar ênfase às formas de comunhão, importantíssimas no viver quotidiano.

Quando estudamos um território, é importante abordar o mito do Minotauro. Ele foi muito bem estudado por Andre Siganos em seu livro Le Minotaure et son mythe e por Gilbert Durand em Polysémie de l'objet 
symbolique, é um dos mitos que mais se aproxima das cidades contemporâneas, porque ele nos mostra e nos explica pela sua violência, «que ele evoca de maneira catártica o que se nutre de nós, [...] o que palpita em nós, nos aterroriza e nos fascina ${ }^{1}$. Esta relação à violência nos leva à transgressão tal como Georges Bataille a define como sendo divina - ela não tem nada de racional e nos leva também a Dionísio, «o deus da festa, o deus da transgressão religiosa $»^{2}$.

Com o objetivo de observar as imagens, através da simbolização do arquétipo do monstro devorante, encontramos figuras de excesso como da brutalidade e da crueldade. Enquanto que através do refúgio encontramos lugares de encontro ou de proteção. Nos territórios onde a pesquisa foi realizada, a consolidação das figuras de excesso nos levou aos espaços onde elas vibram, poderíamos dizer que estes lugares lembram o centro do labirinto, a casa do Minotauro, quero dizer, o espaço urbano no seu sentido o mais labiríntico, o mais enraizado. Percebemos através das pesquisas que o interesse não é mais de procurar a transparência, através do fio de Ariadne que ajudou Teseu a matar o Minotauro, mas de viver emoções.

Habitada por diversos lugares de encontro, a cidade de hoje oferece ambientes diferentes onde grupos de pessoas vão se encontrar e dividir suas emoções, tudo isso segundo suas afinidades que passam antes pelo campo emocional e muitas vezes festivo em vez de passar somente pelo racional/funcional. Isso nos convida a realizar uma leitura sensível do território permitindo ressaltar os lugares de convívio. Estas diversas formas de estética que encantam a vida em grupo, ou seja, a vida tribal, nos leva a questionar a essência do local onde é vivida a experiência comum, experiência que viria acompanhada de Eros ou do cortejo de Dionísio. Sem esquecer do axé dos orixás que trazem os elementos da natureza consigo.

É evidente que lógicas puramente afe- tivas organizam o espaço cotidiano. Que espaços são estes? O que traz a dimensão de hospitalidade na arquitetura? Isto nos leva a questionar a dimensão simbólica do espaço. O símbolo como o espaço se caracterizam pela sua ambigüidade. Esta ambigüidade faz com que o espaço seja vivido de maneira diferente segundo a cultura do morador. Então, segundo o regime da imagem que o habitante pertence, a simbologia do espaço muda. Segundo Gilbert Durand, "ao regime heróico da antítese vai suceder o regime plenário do eufemismo"3 , e é a linguagem eufêmica que vai caracterizar o estudo do espaço no Brasil. Esta linguagem eufêmica é obrigatoriamente ambígua, porque ela procede através de inversões.

O espírito de contradição e de ambigüidade presente no viver quotidiano do brasileiro deve ser levado em conta, como também a ambivalência de Eros-Cronos-Tanatos que são ligados ao nosso destino mortal onde, segundo Gilbert Durand, o rosto ameaçador do tempo pode ser exorcizado de duas maneiras diferentes: uma fazendo referência ao regime diurno da imagem e a outra ao noturno. Ele mostra que "os dois Regimes da imagem são então os dois aspectos dos símbolos da libido. O desejo de eternidade tanto compõe com a agressividade, a negatividade, transferida e objetivada, do instinto de morte para combater Eros noturna e feminoíde" ... “ou ao contrário a libido irá compor com as suavidades do tempo, trocando como que do interior o regime afetivo das imagens da morte, da carne e da noite, é quando o aspecto feminino e maternal da libido será valorizado, que os schèmes imaginários vão se curvar no sentido da regressão e a libido sob este regime se transfigurará em um símbolo maternal" ${ }^{4}$.

A cidade noturna ou diurna é composta por lugares que são investidos por grupos, tribos, que estão lá por causa de uma razão emocional, de um sentimento que não tem nenhuma explicação racional. Isto acontece com freqüência quando abordamos lugares de festa, porque é um local de transgressão. 
Sabe-se que o ser humano vive em relação à morte, por isto a importância de abordarmos o sentimento de angústia na frente da morte, a partir do inconsciente coletivo (Jung). Em decorrência de uma pesquisa de terreno realizada no Morro da Conceição ${ }^{5}$, encontramos elementos que ilustram esta ambigüidade do viver brasileiro. O método de pesquisa utilizado é baseado no sistema de classificação das imagens elaborado por Gilbert Durand e a partir dele surgiu o AT- ${ }^{6}$, teste projetivo criado por Yves Durand, baseado em arquétipos universais e adaptado por Danielle Rocha Pitta para o tecido urbano. Os nove arquétipos empregados no teste são os seguintes:o monstro devorante e a queda, que diz respeito à angústia existencial em frente à passagem do tempo e da morte. A espada, o refúgio e o elemento cíclico conduzem à ação. $\mathrm{O}$ personagem é o suporte para a projeção do indivíduo projetado. A água, o animal e o fogo são os elementos polissêmicos e polimorfos.

Já que o At-9 tem como base os arquétipos para estimular o ato criativo, ele exprime igualmente o inconsciente coletivo. Os resultados das entrevistas realizadas com os habitantes das cidades citadas - sabendo que cada morador desenhou os nove arquétipos no mapa de seu bairro ressaltam, no que diz respeito à simbolização da queda, por exemplo, tanto um terremoto quanto uma escorregada no escorrego. Veremos um pouco mais longe a representação da queda e suas características específicas para cada território. $\mathrm{O}$ arquétipo do monstro devorante nos levou aos lugares de violência, de droga ou ainda aos espaços ligados a elementos que fazem pensar na Morte e no tempo angustiante. Este arquétipo teve quase sempre a função de nos mostrar simbolicamente quais são as inquietudes dos moradores.

Para ilustrar este trabalho, vejamos primeiro o exemplo de Noto, território inteiramente barroco na sua arquitetura, onde o terremoto e pedras que caem simbolizaram a queda na maior parte dos ca- sos. Enquanto que cachorros ou figuras antropomorfas representaram várias vezes o monstro devorante. Sua representação e seus símbolos foram bastante heterogêneos e sem unanimidade. $\mathrm{O}$ medo quotidiano do terremoto representado pela queda deve ter substituído o monstro que se encontrou indefinido. A imagem do terremoto é bastante forte, ele não é somente físico mas também moral, "quando o chão não é mais sólido, os espíritos também erram e vagabundam"7. Os monstros das esculturas de Noto, que são específicos desta região, parecem ter guardado a expressão de medo em suas caretas.

Um dos lugares considerados mais importantes para os habitantes de Noto é a catedral: "Chiesa St. Nicolo". Em 1998 ela se encontrava com um pedaço de cúpula erguido contra o céu, em conseqüência de uma sucessão de terremotos e de um alicerce que, com o escorrimento da água da chuva, rachou a estrutura do prédio. Este desabamento aconteceu em 1996.

Normalmente uma catedral é considerada como um lugar de espiritualidade, um refúgio. A grande maioria dos símbolos que lhe foram atribuídos se referem à angústia provocada pela queda da cúpula, ela mesma atribuída aos terremotos. Esta queda parece ter tido como conseqüência uma inversão simbólica que transformou o que deveria ser um refúgio, ou um lugar de vida espiritual, em um lugar marcado pela angústia.

O refúgio representou em $80 \%$ das entrevistas a segurança e a proteção. Em seguida, raramente, encontramos um esconderijo, o repouso e a solidão. Ele foi quase sempre representado por grutas.

Partirmos agora a Paris, ao bairro de Belleville onde a diversidade sociocultural apreende os moradores, isto existe por causa da vontade de viver os diversos passados do bairro. Belleville vive de três passados que a caracteriza seu passado de cultivador de vinho marcado pelas festas e pelo vinho: poderíamos imaginar que Dionísio era bastante presente no século XVIII. O se- 
gundo fato que marca sua memória é a 'Commune', evento popular histórico marcado pelo entusiasmo e pelo vigor da 'Internationale Ouvrière'. E para terminar, este século é marcado pela imigração: de russos, judeus, árabes, iugoslavos, asiáticos, entre outros. Hoje, Belleville é um bairro onde vários artistas moram, onde eles procuram a diversidade.

No Ocidente, segundo Yves Durand, o sentido atribuído à queda é de origem judaico-cristã, ela é associada ao tema da "punição, introduzindo assim toda a concepção maniqueísta do sistema moral do Ocidente judeu-cristão"8. Estas quedas, de conotação negativa, são representadas por indivíduos que caem e que se machucam fisicamente ou por quedas simbólicas que fazem referência à sociedade. Elas se encontram em lugares considerados perigosos no bairro, como a rua 'des Envierges', a 'Villa Faucheurs', a rua 'des Couronnes', perto do parque, o CFDT (sede do sindicato), que acolhe também os sem domicílio fixo (S.D.F.) e o 'boulevard de Belleville', onde tem a feira. A queda, segundo as respostas obtidas pela pesquisa, é principalmente ligada à violência.

Os monstros representam o medo e estão ligados ao cotidiano, ao medo da violência, do mal; eles foram representados por cachorros (pitbulls) ou por pessoas. A angústia em Belleville foi freqüentemente ligada à violência do bairro. Nem a imagem da morte nem do fantasma foram representadas como em alguns casos em Noto, onde as imagens do monstro foram heterogêneas e quase sempre em forma de cachorro ou de figuras antropomorfas como as ornamentações barrocas dos edifícios. O monstro devorante, ao contrário da queda que se encontrou em lugares fixos, ficou disperso no bairro da mesma forma que a queda negativa. Poderíamos concluir a partir disto que o ' $\mathrm{mal}^{\prime}$ se encontra no bairro inteiro. $\mathrm{O}$ elemento cíclico só serviu para dar mais ênfase a tudo isto: ele faz referência às subidas regulares de violência.

A rua 'des Couronnes' acolhe igual- mente algumas imagens de violência e de droga, grupos de jovens ficam por lá sem ter nada para fazer, este é o setor que dá acesso à pequena subida na natureza a qual conduziria ao monstro, se fizermos alusão ao mito do Minotauro. As ruas paralelas são calmas e o ambiente muda.

O refúgio em Belleville representa quase sempre a proteção, como em Noto. Ele não foi sempre desenhado na casa do morador, mas também no parque ou na casa de um amigo.

Vindo agora para Recife e subindo um de seus morros, chegamos no Morro da Conceição. A angústia ficou concentrada na rua da Mocidade com personagens e barreiras que caem. Encontramos também o mal, o medo e a violência representados por animais ou por um revólver. É importante ressaltar a imagem da fofoqueira, bastante cruel e freqüente aqui no Brasil.

As lendas contadas pelos habitantes são também muitas vezes cruéis. A mais falada foi a da 'Cumadre Fluorzinha', uma menina que é assassinada violentamente pelo pai. Seu espírito então, dominado pela mesma raiva que a do seu pai quando a matou, tormenta seu pai até ele se suicidar. Hoje, seu espírito vagueia. Segundo os moradores do bairro, em qualquer lugar que estejamos, se pronunciarmos seu nome, nós nos perdemos, não encontramos mais o caminho de casa, ficamos chorando, perdidos, loucos, e depois de um bom momento de desespero, nos reencontramos.

As imagens que simbolizam esta rua se referem à briga e ao barulho, enquanto que a espada e a espiral têm a função de trazer a paz e a energia positiva. É na necessidade de estabelecer uma complementaridade, um equilíbrio, neste território, que estes elementos se encontram. É nesta vontade de compor com a suavidade do tempo que encontramos aqui, em um local vivido sob uma lógica do eufemismo, imagens contraditórias. É através deste processo de inversão obrigatoriamente ambíguo da linguagem eufêmica que o estudo do espaço urbano é possível no Brasil. 
É notável que nem um personagem passeia por esta rua, os personagens estão espalhados pelo bairro mas nemnhum se encontra na rua da Mocidade, como é o caso do refúgio. Ninguém se refugia nesta rua também. Encontramos através dos arquétipos polissêmicos e polimorfos as festas e o boêmio. Os moradores falaram da festa de São João, do bar e da força espiritual. Encontramos também a imagem da inquietude e da guerra animada por um gato negativo, que em Recife representa o Diabo.

No Morro da Conceição, o refúgio representa proteção também, mas só em $20 \%$ dos casos. Também é um esconderijo na mesma proporção. Depois encontramos tranqüilidade e lugar bom de alegria. Encontramos um refúgio ambíguo, que é uma moradia com maus elementos. Os refúgios foram representados principalmente por casas, depois serras, abrigo ou mata. Para terminar, igrejas, pessoas dando a mão, parque de diversão, posto de saúde e um banco na praça.

É muito interessante levar em consideração o fato de que na rua da Mocidade não se encontra nenhuma imagem ligada ao arquétipo do personagem ou do refúgio. A rua da Mocidade sendo o lugar do bairro que mais acolheu o monstro devorante, percebese que é bastante animada, porém ninguém se refugia nem passeia nela.

A eufemização da morte pelo trágico, através da festa, nos leva ao desejo de eternidade através do amor. Gilbert Durand explica muito bem este fato, ele diz que "o desejo de eternidade parece querer ultrapassar a totalidade da ambigüidade libidinosa e organizar o tornar-se ambivalente da energia vital em uma liturgia dramática que totaliza o amor, o tornar-se e a morte. É então que a imaginação organiza e mede o tempo, mobília o tempo de mitos e lendas históricas, e vem através da periodicidade consolar da fuga do tempo" ${ }^{\prime \prime}$.

Estes lugares, marcados por figuras de excesso que nós destacamos, são como uma dobra no território, eles poderiam ser a representação do centro do labirinto. Tra- ta-se de uma dobra que concentra ao mesmo tempo os excessos de violência e as efervescências festivas. São dobras tal como Michel Maffesoli as descreve "As "dobras » são preservadas pelo que elas são, nichos onde a parte de sombra, individual ou coletiva, pode encontrar refugio" ${ }^{\prime 10}$.

Cidades Diurnas ou cidades Noturnas, o refúgio encontra seus próprios símbolos, é um arquétipo que permite orientações simbólicas diferentes. Segundo Yves Durand, "para o imaginário heróico o refugio será sempre um « refúgio contra » um perigo; para o imaginário místico ele fica uma imagem do contém simbolizando o bem-estar e a vida prazerosa"11.

O Minotauro destrói o princípio de contradição. Ele tanto pode ser sensual e noturno quanto um monstro agindo com toda sua violência sacrifical. Parece que hoje ele goza do seu aspecto noturno •

\section{Notas}

1 Andre Siganos, Le Minotaure et son mythe. Puf, Paris, 1993, p. 145.

2 Georges Bataille, Les larmes d'Eros. 10, 18, Paris, 2000, lère. édition, 1978, p. 95.

3 Gilbert Durand, Les Structures Anthropologiques de l'Imaginaire, p. 220.

4 As últimas citações são de Gilbert Durand, Les structures... ver as p. 219 à 224.

5 Ver sobre este assunto: Gilbert DURAND, Les Structures anthropologiques de l' imaginaire ; Yves DURAND, L'exploration de l'imaginaire, L'Espace Bleu, 1988. ; Danielle ROCHA PITTA, Para uma arquitetura sensível. In: Imaginário e complexidade, (org.) ROCHA PITTA,D.e LOPES NOGUEIRA, M. A., Universidade Federal de Pernambuco, Recife, 1998.

6 Cf. Durand, Y., L'Exploration de l'Imaginaire. L'Espace Bleu, 1988.

7 Michel Maffesoli, Du nomadisme, vagabondages initiatiques. 
Libr. Générale Française, Paris, 1997, p. 86.

8 Yves Durand, L'exploration de l'imaginaire, $p .52$.

9 Gilbert Durand, Les structures... p.224.

10 La part du Diable. Précis de subversion postmoderne. Flammarion, Paris, 2002. p. 133.

11 DURAND, Y., L'exploration de l'Imaginaire, op. cit., p. 59.

\section{Referências}

BATAILLE, Georges. Les larmes d'Eros. 10, 18, Paris, 2000, $1^{\text {̀̀re }}$. édition, 1978.

DURAND, G. e SUN, C. Mythes, thèmes et variations. Desclée de Brouwer, Paris, 2000.

Les Structures Anthropologiques de l'Imaginaire. Dunod, Paris, 1992.

DURAND, Y. L'exploration de l'imaginaire, L'Espace Bleu, 1988.

MAFFESOLI, M.. Le temps des tribus. Le déclin de l'individualisme dans les sociétés postmodernes. La Table Ronde, 2000.

La part du Diable. Précis de subversion postmoderne. Flammarion, Paris, 2002.

Notes sur la postmodernité, le lieu fait lien. Éd. du Félin / Institut du monde arabe, Paris, 2003.

Du nomadisme, vagabondages initiatiques. Libr. Générale Française, Paris, 1997.

ROCHA PITTA, D. Para uma arquitetura sensível. In. Imaginário e complexidade, (org.) ROCHA PITTA, D.e LOPES NOGUEIRA, M. A. Universidade Federal de Pernambuco, Recife, 1998.

SIGANOS, André. Le Minotaure et son mythe. Puf, Paris, 1993. 